\title{
Drawing the krtań: Laryngeal alternations in Polish
}

\author{
Andrew Lamont \\ University of Massachusetts Amherst
}

\section{Introduction}

Polish exhibits the cross-linguistically common processes of final devoicing and voice assimilation. Notably, these target not only obstruents and obstruent clusters, but also certain obstruent-sonorant (OS) clusters. Unless noted, data are drawn from Gussmann (2007) and represent the dialect spoken in Warsaw.

Examples of final devoicing targeting obstruents and OS clusters are given in (1-2), respectively. Underlying forms are evident from the intervocalic contexts in the left columns. Though not shown in (2), final voiceless OS clusters vary with voiced forms: [bupr] [bubr] 'beaver' (Gussmann, 2007; Cyran, 2014).
a. dux-u 'spirit (loc.)'
c. xleb-a 'bread (gen.)'
e. wask-a
'grace'
b. dux 'spirit'
d. xlep 'bread'
g. muzg-om
'brain (dat. pl.)'
f. wask
h. musk 'brain'
a. $\quad v^{j}$ atr-u
'wind (gen. sg.)'
c. plot-w-e-m 'I wove'
e. bobr-a 'beaver (gen. sg.)'
g. mog-w-a 'she could'
b. $\mathrm{v}^{\mathrm{j} a t r}$
b. wato 'wind'
d. plut-wo
f. bupr
'he wove'
h. muk-w 'he could'

Obstruent clusters must agree in voice; examples of assimilation are given in (3). Assimilation targets tautomorphemic clusters created by vowel loss (3a-d), clusters across morpheme boundaries (3e-1), and clusters across word boundaries $(3 \mathrm{~m}-\mathrm{t})$. In these data, assimilation is regressive and is not limited to voiced or voiceless triggers, ${ }^{1}$ though there are exceptions.

\begin{tabular}{|c|c|c|c|c|c|}
\hline $\begin{array}{l}\text { a. } \\
\text { c. }\end{array}$ & $\begin{array}{l}\text { udzets } \\
\text { t } \int e r v^{j} \varepsilon t s\end{array}$ & $\begin{array}{l}\text { 'haunch, leg' } \\
\text { 'June' }\end{array}$ & & $\begin{array}{l}\text { utcts-a } \\
\text { t } \varepsilon r f t s-a\end{array}$ & $\begin{array}{l}\text { 'haunch, leg (gen. sg.)' } \\
\text { 'June (gen. sg.)' }\end{array}$ \\
\hline e. & wap-a & 'paw' & f. & wap-k-a & ‘paw (dim.)’ \\
\hline g. & $3 a b-a$ & 'frog' & h. & 3ap-k-a & 'frog (dim.)' \\
\hline i. & pro6-i-tc & 'ask' & j. & proz-b-a & 'request (noun)' \\
\hline k. & groz-i-tc & 'threaten' & 1. & groz-b-a & 'threat' \\
\hline $\mathrm{m}$. & sklep-i & ‘shop (nom. pl.)’ & n. & sklep spo3ift $\mathrm{i}$ & 'grocer's' \\
\hline o. & vrog-a & 'enemy (gen. sg.)' & p. & vruk publitfni & ‘public enemy’ \\
\hline q. & $k \supset \int-\varepsilon$ & 'basket (nom. pl.)' & r. & ko3 boruvek & ‘basket of berries’ \\
\hline s. & zbudz-i & 's/he will wake' & t. & zbudz brata & 'wake the brother!' \\
\hline
\end{tabular}

Like obstruent clusters, obstruent-sonorant-obstruent (OSO) clusters are under the same pressure to agree in voice; examples are given in (4). Static agreement is seen in tautomorphemic clusters (4a-b) and assimilation is evident across morpheme boundaries (4c-d) and across word boundaries (4e-h). In the alternations in (4c-h), the stem-final OS cluster assimilates to the following obstruent; this is also variable. ${ }^{2}$ Not all OSO clusters agree in voice: the data in (4i-1) demonstrate an asymmetry. In OS\#O clusters, where \#

\footnotetext{
* I am grateful to Gaja Jarosz, without whom this project would not exist. This work has benefited greatly from discussions with Gaja, members of the University of Massachusetts phonology community, and attendants of AMP 2017, as well as comments from four anonymous reviewers. All remaining errors are of course my own.

1 Across morpheme boundaries, there is an imbalance towards [-voice] targets. The nominalizing suffix [-ba], as in (3j,1), is not productive (Cyran, 2014). The context for voicing is limited to the conditional enclitic [-bi] , and it is unclear whether assimilation occurs in that environment (Gaja Jarosz p.c.).

2 In a phonetic study, Strycharczuk (2012) found that multiple factors influence these alternations, arguing that a purely phonological account is inadequate.
}

(C) 2018 Andrew Lamont

Proceedings of AMP 2017 
represents a word boundary, the OS cluster assimilates (cf. [p'jotr-a] 'Peter (gen.)' and [gavr-a] 'bear's lair'), and the entire cluster agrees in voice $(4 \mathrm{i}, \mathrm{k})$. In O\#SO clusters, the final obstruent is voiceless (cf. [ $\mathrm{v}^{\mathrm{j}} \mathrm{id}$ ok-u]

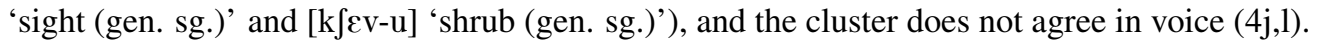

\begin{tabular}{|c|c|c|c|c|c|}
\hline a. & krtap & 'larynx' & b. & drv-a & 'pieces of wood' \\
\hline c. & mondr-i & 'wise' & d. & mentr- $-\mathfrak{i}$ & 'wiser' \\
\hline e. & $\mathrm{v}^{\mathrm{j}}$ atr fsxodji & 'easterly wind' & f. & $\mathrm{v}^{\mathrm{j}} \mathrm{adr}$ zaxodji & 'westerly wind' \\
\hline g. & bojazn p pet & 'fear of' & h. & bојаzл bəza & 'fear of God' \\
\hline i. & $\mathrm{p}^{\mathrm{j}} \mathrm{Jdr}$ daje & 'Peter gives' & $\mathrm{j}$. & $\mathrm{v}^{\mathrm{j}} \mathrm{idok} \mathrm{mgwi}$ & 'sight of mist' \\
\hline $\mathrm{k}$. & gavr dalecix & 'distant lair (gen. pl.)' & 1. & $\mathrm{k} \int \varepsilon f$ rdestu & 'knotgrass shrub' \\
\hline
\end{tabular}

The role sonorants play in these data has been debated. While some analyses treat the voiceless sonorants in (2) and (4) as a purely phonetic phenomenon (Lombardi, 1991, 1995; Cyran, 2014), others have argued that sonorants are phonologically active (Rubach \& Booij, 1990a; Bethin, 1992; Rubach, 1996, 1997; Gussmann, 2007). However one approaches these data, the fact that voice assimilation sometimes occurs through sonorants and sometimes does not needs to be accounted for.

Representative of the latter, Rubach (1996) gives a rule-based analysis of the asymmetry in OSO clusters as an interaction between prosodification and assimilation. In clusters with marked sonority profiles, sonorants are adjoined to the phonological word rather than syllabified. Adjunction is divided into two rules: Initial Adjunction targets sonorants at the left edge of the word, and Housekeeping Adjunction at the right edge. Once incorporated into the prosodic structure, sonorants acquire laryngeal nodes. Voice Assimilation targets obstruents that are adjacent on the laryngeal tier, and applies between the adjunction rules.

The basic rule interaction is illustrated in (5) with $/ \mathrm{p}^{\mathrm{j}}$ otr daje/ $\rightarrow$ [ $\mathrm{p}^{\mathrm{j}}$ odr daje] 'Peter gives' (4i) and $/ \mathrm{v}^{\mathrm{j}}$ idok mgwi $/ \rightarrow$ [v'idok mgwi] 'sight of mist' $(4 \mathrm{j})$; phonological words are indicated with angled brackets \langle\rangle . With the OS\#O cluster, Voice Assimilation applies before the word-final sonorant adjoins to the phonological word. At that point, the obstruents are still adjacent on the laryngeal tier; the sonorant does not block assimilation because it does not yet have a laryngeal node. With the O\#SO cluster, the word-initial sonorant adjoins earlier in the derivation, intervening between the two obstruents on the laryngeal tier. This bleeds Voice Assimilation, and the first obstruent surfaces faithfully voiceless. While these rules model whether sonorants are blockers, additional rules are needed to account for their voicelessness in (2) and (4), as well as final devoicing.

\begin{tabular}{|c|c|c|}
\hline$/ \mathrm{p}^{\mathrm{j}}$ otr daje/ & $/ \mathrm{v}^{\mathrm{j}} \mathrm{id} \mathrm{k}$ mgwi $/$ & \\
\hline$\left\langle\mathrm{p}^{\mathrm{j}}\right.$ ot $\rangle \mathrm{r}\langle$ daje $\rangle$ & $\left\langle v^{j}\right.$ idok $\rangle \mathrm{m}\langle$ gwi $\rangle$ & Prosodification \\
\hline & $\left\langle\mathrm{v}^{\mathrm{j}} \mathrm{idok}\right\rangle\langle\mathrm{mgw} \dot{\mathrm{i}}\rangle$ & Initial Adjunction \\
\hline$\left\langle\mathrm{p}^{\mathrm{j}} \mathrm{od}\right\rangle \mathrm{r}\langle$ daje $\rangle$ & & Voice Assimilation \\
\hline$\left\langle\mathrm{p}^{\mathrm{j}} \mathrm{odr}\right\rangle\langle$ daj $\varepsilon\rangle$ & & Housekeeping Adjunction \\
\hline
\end{tabular}

This approach captures the pattern, but leaves open the possibility of the opposite asymmetry. By reversing the order of Initial Adjunction and Housekeeping Adjunction, Voice Assimilation would target obstruents in O\#SO but not OS\#O clusters. It is also unclear how well this analysis translates into a constraint-based framework like Optimality Theory (OT) or Harmonic Serialism (HS) (Prince \& Smolensky, 1993/2004; McCarthy, 2000). Constraint-based analyses of syllabification and prosodification have relied on a single markedness constraint, PARSESEG, to motivate incorporating segments into prosodic structure (Prince \& Smolensky, 1993/2004; Elfner, 2009; Torres-Tamarit, 2012). For voice assimilation to interrupt prosodification, additional PARSE constraints would have to be posited, or, following Rubach's 1997 analysis, the grammar would have to be equipped with different constraint rankings throughout the derivation.

This paper argues for an alternative account in Harmonic Serialism. Following Rubach (1996), sonorants are analyzed as acquiring laryngeal nodes in the derivation, but, rather than inhibiting agreement between obstruents, these facilitate voice agreement by creating contiguous chains of laryngeal nodes. The mechanism underlying this analysis is a pressure for consonants immediately following obstruents to bear laryngeal nodes, embodied by a novel markedness constraint HAVELAR. HAVELAR is satisfied by linking laryngeal nodes from adjacent obstruents onto sonorants or by inserting laryngeal nodes (see $\S 2$ ). The asymmetry between OS\#O and O\#SO clusters follows from independently motivated positional faithfulness constraints that conflict with HAVELAR word-initially. All sonorants in OS clusters are under the same pressure to bear laryngeal nodes, but in O\#SO clusters, the sonorant is shielded by positional faithfulness constraints. 
This explains the asymmetry rather than stipulating it. Further, this analysis straightforwardly models other patterns in Polish and neatly captures a dialectal difference with a single constraint reranking.

The rest of the paper is structured as follows. Section 2 gives the analysis of the data presented in this section. Section 3 presents presonorant voicing in prepositions and in the Cracow dialect and demonstrates how the analysis captures these data. Sections 4 and 5 discuss the analysis and conclude.

\section{Analysis}

This section presents an analysis of the final devoicing and voice assimilation data laid out in $\S 1$ in Harmonic Serialism (HS) (Prince \& Smolensky, 1993/2004; McCarthy, 2000). ${ }^{3}$ In HS, GEN is limited to producing candidates that differ from the input by the application of a single operation. For this reason, it is important to make the set of operations and constraints explicit. Representationally, this analysis follows Rubach (1996) in assuming a binary voice feature [ \pm voice] that is housed on a laryngeal node [LAR]. There are five operations in GEN relevant to the analysis here, one targeting voice features, and four targeting [LAR] nodes. The set of operations represents a hybrid system that treats voice features as attributes and laryngeal nodes as entities (McCarthy, 2008).

Voice features can be changed, i.e. [ $\alpha$ voice $] \rightarrow[\neg \alpha$ voice]; this operation violates the faithfulness constraint IDENT(VOICE). ${ }^{4}$ When the voice feature is associated with a consonant in a syllable onset, this operation also violates IDENT(VOICE)-ONSET (Beckman, 1998; Wheeler, 2005a,b). Syllabification is taken to occur earlier in the derivation, so onset position is defined over the input not the candidates (Jesney, 2011).

[LAR] nodes can be deleted, violating MAX(LAR). There are also operations to insert new [LAR] nodes or link existing nodes onto adjacent segments; these operations violate DEP(LAR) and NOLINK(LAR), respectively. When a [LAR] node is inserted or spread onto a word-initial consonant, these operations also violate DEP(LAR)-INITIAL and NOLINK(LAR)-INITIAL, respectively (Casali, 1997). Finally, two adjacent [LAR] nodes can be fused, violating UNIFORMITY(LAR). Fusing [LAR] nodes with different specifications of [voice] also violates IDENT(VOICE).

2.1 Final devoicing Final devoicing results from the interaction between the markedness constraint against voiced [LAR] nodes, $*$ [+VOICE], defined in (6), and the IDENT constraints.

(6) $*$ [+VOICE]: Assign one violation for every [LAR] node specified as [+voice].

The basic interaction is shown in tableaux (7) and (8) for /xleb/ $\rightarrow$ [xlep] 'bread (gen.)' (1d) and $/$ dux/ $\rightarrow$ [dux] 'spirit' (1b), respectively. ${ }^{5}$ Laryngeal nodes are represented with capital letter L's attached to segments; only relevant nodes are shown. In tableau (7), the fully faithful candidate [xleb] (7a) fatally violates * [+VOICE], and loses to the devoiced candidate [xlep] (7c). The devoiced candidate is preferred to a phonetically identical candidate in which the laryngeal node associated with the coda is deleted (7b). The optimal candidate serves as input to the next step (not shown), where the derivation converges. In tableau (8), the voiced obstruent is in onset position, and the fully faithful candidate [dux] (8a) is optimal. The unfaithful candidates, both phonetically [tux], improve on *[+VOICE], but fatally violate MAX(LAR) (8b) or IDENT(VOICE)-ONSET (8c). Due to positional faithfulness, only consonants in coda position devoice.

(7)

\begin{tabular}{|c|c|c|c|c|}
\hline $\begin{aligned} \mathrm{xlgb} \\
\mathrm{L} \\
\mathrm{L}\end{aligned}$ & $\begin{array}{l}\tilde{z} \\
0 \\
\varrho\end{array}$ & $\sum_{\Sigma}^{x}$ & $\begin{array}{l}\bar{\sigma} \\
\overrightarrow{+} \\
*\end{array}$ & $\begin{array}{l}\vec{z} \\
\text { 音 }\end{array}$ \\
\hline a. $\begin{aligned} x l \varepsilon b \\
L\end{aligned}$ & & & $\mathrm{~W} 1$ & L \\
\hline b. xlep & & $\mathrm{W} 1$ & & $\mathrm{~L}$ \\
\hline$\rightarrow$ c. $\quad{ }^{\text {xlep }}$ & & & & 1 \\
\hline
\end{tabular}

(8)

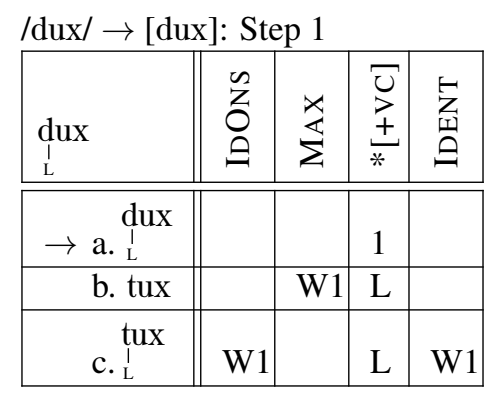

\footnotetext{
3 See McCarthy (2016) for an overview of Harmonic Serialism.

4 For space, all the constraint names are shortened in tableaux.

5 In inputs, obstruents are given with underlying laryngeal nodes, and sonorants without them. This is a source of friction with Richness of the Base, but one that can be accounted for via Lexicon Optimization (Inkelas, 1995).
} 
Inputs with underlyingly voiced clusters must pass through additional derivational steps, as GEN cannot devoice more than one segment at a time. This is shown in tableaux (10-11) with /muzg/ $\rightarrow$ [musk] 'brain' (1h). In the first step, the fully faithful candidate [muzg] (10a) is dispreferred because it contains two voiced [LAR] nodes. The unfaithful candidates all fare better on * [+VOICE]. The two candidates with one voiceless obstruent, both phonetically [musg], are ruled out by MAX(LAR) (10b), or, by creating a cluster that disagrees in [voice], AgreE(VOICE) (10c). AGREE(VOICE) is defined in (9); the deletion candidate (10b) does not violate AGREE[VOICE] because it does not have any adjacent [LAR] nodes. Fusing the two [LAR] nodes is optimal, and candidate (10d) serves as input to the next step of the derivation (11).

(9) AgREe[VOICE]: Assign one violation for every pair of adjacent [LAR] nodes that disagree in [voice].

(10)

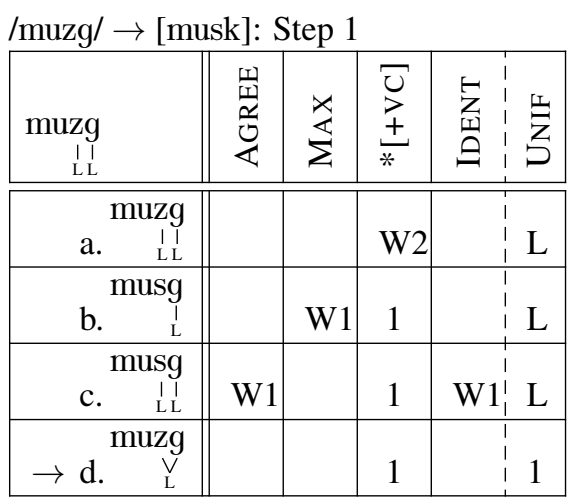

(11)

\begin{tabular}{|c|c|c|c|c|}
\hline$\underset{\substack{\text { muzg } \\
\text { L }}}{ }$ & 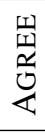 & $\underset{\Sigma}{\stackrel{x}{\Sigma}}$ & $\begin{array}{l}\bar{U} \\
\dot{x} \\
*\end{array}$ & 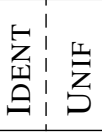 \\
\hline muzg & & & & i \\
\hline a. $\quad \underset{\mathrm{L}}{\mathrm{V}}$ & & & W1 & L ! \\
\hline b. musk & & W1 & & L ! \\
\hline$\rightarrow$ c. $\stackrel{\text { musk }}{\underset{\mathrm{V}}{\text { muth }}}$ & & & & $\begin{array}{ll} & 1 \\
1 & 1\end{array}$ \\
\hline
\end{tabular}

Because the input to the second step only has one [LAR] node, (11) is identical to (7). The fully faithful candidate [muzg] (11a) is dispreferred to the unfaithful candidates by * [+VOICE]. Deleting the shared [LAR] node fatally violates MAX(LAR) (11b), and devoicing is optimal (11c).

Because GEN is limited to changing one [voice] feature at a time, the candidate set for /muzg/ does not contain the voiceless candidate [musk]. Inputs with multiple voiced segments must first pass through a fusion step in order to devoice. Fusion and devoicing both improve on * [+VOICE].

With final OS clusters, the analysis already captures the devoicing of the obstruent, provided it is not syllabified as an onset. This relies on the prosodic nature of IDENT(VOICE)-ONSET, which is defined in terms of syllable position, and not as presonorant faithfulness (Lombardi, 1999; Rubach, 2008). In words with underlyingly voiced OS clusters, two segments are devoiced, which requires at least two derivational steps. The first step spreads the [LAR] node associated with the obstruent onto the sonorant to satisfy the markedness constraint HAVELAR, defined in (12). This shared node is then devoiced in the second step.

(12) HAVELAR: Assign one violation for every consonant without a [LAR] node that is immediately preceded by an obstruent.

Tableaux (13-14) demonstrate this derivation with /bubr/ $\rightarrow$ [bupr] 'beaver' (2f). In the first step, the fully faithful candidate (13a) violates HAVELAR, because its sonorant is not associated with a [LAR] node. The unfaithful candidates satisfy HAVELAR by inserting a [LAR] node (13b) and by spreading the [LAR] node from the obstruent onto the sonorant (13c). Because DEP(LAR) dominates NoLINK(LAR), spreading is optimal, and candidate (13c) serves as input to the next step (14). For space, a non-optimal devoicing candidate that satisfies $*[+$ VOICE $]$ is not shown. The second step is no different from tableaux (7) and (11); devoicing $(14 \mathrm{c})$ is preferred to [LAR] node deletion (14b), and the faithful violation of * [+VOICE] (14a).

\begin{tabular}{|c|c|c|c|c|c|}
\hline $\begin{array}{c}\text { bubr } \\
1 \\
L\end{array}$ & 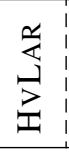 & 离 & 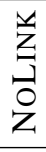 & $\begin{array}{l}\tau \\
⿱ \\
+ \\
*\end{array}$ & $\begin{array}{l}\stackrel{-}{Z} \\
\stackrel{T}{\Theta}\end{array}$ \\
\hline a. $\begin{array}{c}\text { bubr } \\
\frac{1}{L}\end{array}$ & $\mathrm{~W} 1$ & & $\mathrm{~L}$ & 1 & \\
\hline b. $\begin{array}{r}\text { bubr } \\
11 \\
\mathrm{LL}\end{array}$ & & W1 & $\mathrm{L}$ & $\mathrm{W} 2$ & \\
\hline$\rightarrow$ c. $\quad \underset{\mathrm{L}}{\mathrm{bubr}}$ & I & & 1 & 1 & \\
\hline
\end{tabular}

(14) $/$ bubr/ $\rightarrow$ [bupr]: Step 2

\begin{tabular}{|c|c|c|c|c|}
\hline$\underset{\mathrm{L}}{\mathrm{bubr}}$ & 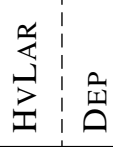 & 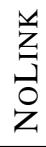 & 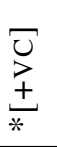 & $\begin{array}{l}5 \\
\mathbf{z} \\
\hat{\theta}\end{array}$ \\
\hline a. $\underset{\mathrm{L}}{\mathrm{bubr}}$ & $\begin{array}{l}1 \\
1 \\
1\end{array}$ & & W1 & $\mathrm{L}$ \\
\hline b. bupr & W1! & & & $\mathrm{L}$ \\
\hline$\rightarrow$ c. $\stackrel{\substack{\text { bupr } \\
\mathrm{L}}}{\mathrm{v}}$ & $\begin{array}{l}1 \\
1 \\
1\end{array}$ & & & 1 \\
\hline
\end{tabular}


Words with final OS clusters, where the obstruent is underlyingly voiceless, as in [ $\mathrm{v}^{\mathrm{j}} \mathrm{atr}_{\mathrm{a}}$ ' wind' (2b), cf. [ $\left.\mathrm{v}^{\mathrm{j}} \mathrm{atr}-\mathrm{u}\right]$ 'wind (gen. sg.)' (2a), only pass through one step before the derivation converges. Spreading the [LAR] node satisfies HAVELAR, and, because voicelessness is unmarked, no further changes are motivated. This makes no commitments about the prosodic status of the final sonorant; it only requires that OS clusters are not analyzed as onsets. The analysis is thus robust to a number of possible prosodification analyses, which are notoriously complex in Polish (Rubach \& Booij, 1990b; Bethin, 2011).

2.2 Voice assimilation Voice assimilation occurs to satisfy AGREE(VOICE). Regressive directionality follows from the positional faithfulness constraint IDENT(VOICE)-ONSET. Tableaux (15) and (16) show assimilation to [+voice] with /kof boruvek/ $\rightarrow$ [ko3 boruvek] 'basket of berries' (3r) and assimilation to [-voice] with /3ab-k-a/ $\rightarrow$ [3apka] 'frog (dim.)' (3h), respectively.

\begin{tabular}{|c|c|c|c|c|c|c|}
\hline 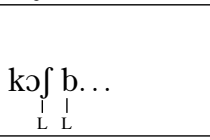 & $\begin{array}{l}\tilde{n} \\
\text { Zn } \\
\varrho\end{array}$ & 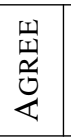 & $\sum_{i}^{x}$ & $\begin{array}{l}\bar{\nu} \\
⿱ 乛 \\
* \\
*\end{array}$ & 飐 & 皇 \\
\hline $\begin{array}{rl} & \mathrm{k} 0 \int_{\substack{L \\
L}} \mathrm{~b} \ldots \\
\mathrm{L} & \mathrm{L}\end{array}$ & & W1 & & 1 & L & $\mathrm{L}$ \\
\hline 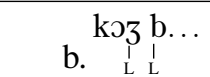 & & & & W2 & 1 & $\mathrm{~L}$ \\
\hline 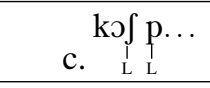 & $\mathrm{W} 1$ & & & $\mathrm{~L}$ & 1 & $\mathrm{~L}$ \\
\hline$\rightarrow$ d. $\stackrel{\mathrm{L}}{\mathrm{k}} \mathrm{b} . .^{\mathrm{b}}$ & & & & 1 & 1 & 1 \\
\hline e. $\stackrel{\mathrm{k} \int \mathrm{L} \ldots}{\mathrm{L}}$ & $\mathrm{W} 1$ & & & L & 1 & 1 \\
\hline f. $\begin{array}{c}\mathrm{k} \int \mathrm{b} \ldots \\
\mathrm{L} \\
\mathrm{L}\end{array}$ & & & $\mathrm{W} 1$ & 1 & L & $\mathrm{L}$ \\
\hline
\end{tabular}

(16) /zab-k-a/ $\rightarrow$ [3apka]: Step 1

\begin{tabular}{|c|c|c|c|c|c|c|}
\hline $\begin{array}{c}\text { 3abka } \\
11 \\
\text { LL }\end{array}$ & $\begin{array}{l}n \\
\\
ٍ\end{array}$ & 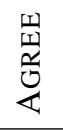 & $\sum^{x}$ & $\begin{array}{l}\tau \\
> \\
+ \\
*\end{array}$ & | & 竞 \\
\hline $\begin{array}{c}3 \text { abka } \\
\text { a. } \quad 11 \\
\mathrm{LL}\end{array}$ & & W1 & & W1 & L & \\
\hline$\rightarrow$ b. $\begin{array}{c}\text { zapka } \\
11 \\
\text { LL }\end{array}$ & & & & & 1 & \\
\hline 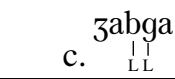 & W1 & & & W2 & 1 & \\
\hline d. ${ }_{\mathrm{L}}^{3 \mathrm{apka}}$ & & & & & 1 & W1 \\
\hline e. ${ }^{3 \mathrm{abga}}$ & W1 & & & W1 & 1 & W1 \\
\hline f. $3^{3 \text { apka }}$ & & & W1 & & $\mathrm{L}$ & \\
\hline
\end{tabular}

In tableau (15), the fully faithful candidate [kJ boruvek] (15a) fatally violates AGREE(VOICE), and is dispreferred to candidates where the obstruent cluster agrees in voice. The application of three different operations derives well-formed clusters. In $(15 \mathrm{~b}, \mathrm{c})$, one of the [voice] features is changed, in $(15 \mathrm{~d}, \mathrm{e})$, the [LAR] nodes are fused, and, in (15f), the first [LAR] node is deleted. Candidate (15f) corresponds to languages where assimilation is asymmetrically only to [-voice] targets (Wetzels \& Mascaró, 2001). Deleting a [LAR] node (15f) is ruled out by MAX(LAR). Though not shown for space, a candidate in which the second [LAR] node is deleted also violates HAVELAR. Candidates $(15 \mathrm{c}, \mathrm{e})$ with voiceless obstruent clusters [kof poruvek] are ruled out by IDENT(VOICE)-ONSET, because the targeted [voice] feature is associated with the onset of borówek. This leaves the candidates with voiced clusters [koz boruvek] (15b,d). Changing the coda [voice] feature is dispreferred to fusing the [LAR] nodes by * [+VOICE], making candidate (15d) optimal. Though not shown, the initial obstruent of kosz also bears a laryngeal node. In candidates with final [3], this initial voiceless [k] does not violate AGREE(VOICE) because the obstruents are separated by a vowel. Adjacency is determined over the string, not on a laryngeal tier, cf. Rubach (1996).

Tableau (16) is very similar to (15). Again, the fully faithful candidate (16a) is ruled out by AgreE(VOICE). Voicing the onset (16c,e) is ruled out by IDENT(VOICE)-OnSET, and deleting either [LAR] node (16f) is ruled out by $\operatorname{MAX}(L A R)$. This leaves candidates $(16 \mathrm{~b}, \mathrm{~d})$ with voiceless clusters, which both violate IDENT(VOICE). Unlike (15), where assimilation is to a marked feature value, fusion does not improve on * [+VOICE], and the superfluous violation of UNIFORMITY(LAR) is fatal for candidate (16d). (16b) is thus optimal. Because fusion violates a faithfulness constraint, it is only motivated when it improves on AGREE(VOICE) or * [+VOICE] (fusion cannot satisfy HAVELAR because it does not associate new consonants to [LAR] nodes). Fusion cannot target [-voice][-voice] clusters, only [+voice][-voice], [-voice][+voice], and [+voice][+voice] clusters. This has consequences for assimilating obstruent clusters.

Underlyingly voiced obstruent clusters assimilate to obstruents across word boundaries; examples are given in (17). As with final devoicing, assimilating obstruent clusters requires additional derivational steps.
a. $\quad g v^{\mathrm{j}} \mathrm{azd}-\mathrm{a}$ 'star'
b. $g v^{j}$ ast-k-a
'star (dim.)'
c. vruz-b-a 'prophecy'
d. vruz-b zwov'j $\varepsilon \int t \int i x$
'ominous prophecy (gen. pl.)' 
There are two derivational paths to assimilate a voiced cluster. The derivation can first pass through a step that fuses [LAR] nodes, which can then be assimilated in one step, or the derivation can assimilate one [LAR] node per step. The fork results from a tie in the first step; both derivations are shown in tableaux (18-20) for /gv ${ }^{j}$ azd-k-a/ $\rightarrow$ [gv ${ }^{j}$ astka] 'star (dim.)' (17b). The derivation splits in the first step, but ultimately converges on the same phonetic output.

\begin{tabular}{|c|c|c|c|c|c|c|c|}
\hline 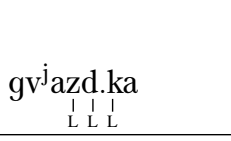 & 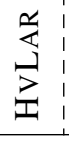 & $\begin{array}{l}n \\
\vdots \\
\varrho\end{array}$ & 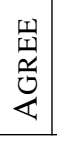 & $\sum_{\Sigma}^{x}$ & $\begin{array}{l}\bar{U} \\
> \\
\pm \\
*\end{array}$ & 崖 & 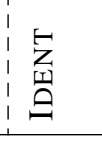 \\
\hline a. $\begin{array}{c}g^{\mathrm{j}} \text { azd.ka } \\
1 \\
\text { L L L L } \\
\end{array}$ & 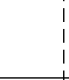 & & 1 & & $\mathrm{~W} 2$ & $\mathrm{~L}(\mathrm{c})$ & L (b) \\
\hline 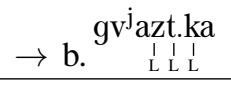 & & & 1 & & 1 & & 1 \\
\hline$\rightarrow c . \quad \underset{L_{L}^{\prime}}{g v^{\mathrm{j}} a z d \cdot k a}$ & 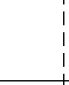 & & 1 & & 1 & 1 & 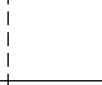 \\
\hline 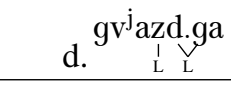 & & W1 & $\mathrm{L}$ & & W2 & 1 & W1 \\
\hline e. $\begin{array}{c}g^{\mathrm{j}} \text { azt.ka } \\
\mathrm{L} \\
\mathrm{L}\end{array}$ & 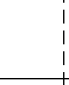 & & 1 & & 1 & 1 & W1 \\
\hline f. \begin{tabular}{c}
$g^{\mathrm{j}}$ asd.ka \\
\multicolumn{1}{l}{$\begin{array}{c}1 \\
\mathrm{~L}\end{array}$}
\end{tabular} & & & 1 & W1 & 1 & $\mathrm{~L}(\mathrm{c})$ & L (b) \\
\hline g. $\begin{array}{c}g^{\mathrm{j}} \text { azt.ka } \\
\begin{array}{c}1 \\
\mathrm{~L}\end{array} \\
\mathrm{~L}\end{array}$ & $\mathrm{~W} 1$ & & $\mathrm{~L}$ & W1 & 1 & $\mathrm{~L}(\mathrm{c})$ & L (b) \\
\hline
\end{tabular}

In the first step (18), the fully faithful candidate $\left[\mathrm{gv}^{\mathrm{j}} \mathrm{azd} . \mathrm{ka}\right](18 \mathrm{a})$ is dispreferred by $*[+\mathrm{VOICE}]$ to candidates with fewer marked [LAR] nodes. The optimal candidates $(18 \mathrm{~b}, \mathrm{c})$ improve on * [+VOICE] by changing one voice feature (18b) or by fusing the two voiced [LAR] nodes (18c). Fusing mismatching [LAR] nodes, as in candidates $(18 \mathrm{~d}, \mathrm{e})$, superfluously violates UNIFORMITY(LAR) or IDENT(VOICE). Given the ranking, to rule out candidate $(18 \mathrm{~d})$, the prevocalic $/ \mathrm{k} /$ must be in onset position, as the period indicates. Deleting the first [LAR] node (18f) is dispreferred by MAX(LAR). Deleting the middle or final [LAR] node (18g) improves on * [+VOICE] and AGREE(VOICE), but fatally violates HAVELAR, because the targeted segments are immediately preceded by obstruents. The optimal candidates serve as inputs to the next steps, which converge on the same output. Candidate (18b) is shown as the input to tableau (19) and candidate (18c) is shown as the input to tableau (20). This tie can be avoided by arbitrarily ranking UNIFORMITY(LAR) and IDENT(VOICE) to favor one of the two candidates.

In tableau (19), the derivation continues by assimilating the remaining voiced obstruent (19b), satisfying AgREE(VOICE) and *[+VOICE]. Because assimilation is to [-voice], fusion (19c) superfluously violates UNIFORMITY(LAR). Deletion (19d) is ruled out by MAX(LAR). Similarly, in tableau (20), assimilating the shared [LAR] node is optimal (20b). Fusion and deletion fatally violate UNIFORMITY(LAR) (20c) and MAX(LAR) (20d). Voicing the onset /k/ (not shown) fatally violates IDENT(VOICE)-OnSET. Both tableaux converge on the same phonetic output $\left[\mathrm{gv}^{\mathrm{j}} \mathrm{astka}\right]$.

\begin{tabular}{|c|c|c|c|c|c|}
\hline 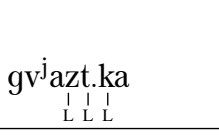 & 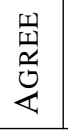 & $\underset{\Sigma}{\infty}$ & $\begin{array}{l} \pm \\
> \\
+ \\
*\end{array}$ & 岂 & 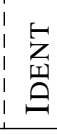 \\
\hline 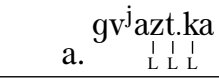 & W1 & & W1 & & $\mathrm{L}$ \\
\hline$\rightarrow$ b. $\begin{array}{c}g^{j} \text { ast.ka } \\
\begin{array}{cll}1 & 1 & 1 \\
L & L & L\end{array}\end{array}$ & & & & & 1 \\
\hline c. $\stackrel{\substack{v^{j} \\
V_{L}}}{\text { ast.ka }}$ & & & & W1 & 1 \\
\hline d. $\begin{array}{c}g^{\mathrm{j}} \text { ast.ka } \\
\begin{array}{c}1 \\
\mathrm{~L}\end{array} \\
\mathrm{~L}\end{array}$ & & W1 & & & $\mathrm{L}$ \\
\hline
\end{tabular}

\begin{tabular}{|c|c|c|c|c|}
\hline 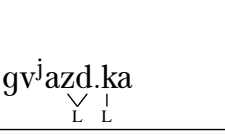 & \begin{tabular}{l} 
崩 \\
$\frac{1}{0}$ \\
\multirow{4}{\varangle}{}
\end{tabular} & $\stackrel{x}{\Sigma}$ & $\begin{array}{l} \pm \\
> \\
\pm \\
*\end{array}$ & 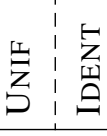 \\
\hline 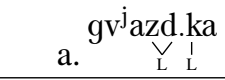 & W1 & & W1 & $\mathrm{L}$ \\
\hline$\rightarrow$ b. $\stackrel{\substack{g^{j} \\
v_{L}^{\prime}}}{V_{L}}$ & & & & 1 \\
\hline c. ${ }^{g v^{j}} \underbrace{\text { ast.ka }}_{\text {L }}$ & & & & $\mathrm{W} 1: 1$ \\
\hline d. $\begin{array}{c}g^{\mathrm{j}} \text { ast.ka } \\
\substack{l \\
\mathrm{~L}}\end{array}$ & & W1 & & L \\
\hline
\end{tabular}


While voiced obstruent clusters can be gradually assimilated, voiceless clusters cannot be. In tableau (18), satisfying AGREE(VOICE) is delayed by gradually improving on * [+VOICE]. With voiceless clusters, fusion and gradual assimilation do not improve on AGREE(VOICE) or * [+VOICE], and so there is no path to assimilation. The examples in (21) demonstrate that across word boundaries, final voiceless clusters do not assimilate. These cannot be accounted for by analyzing / $/$ as a defective trigger, because it does trigger assimilation: [skleb vazivni] 'greengrocer's', cf. [sklep-i] 'shop (nom. pl.)' (3m). There is at least one exception to the generalization that voiceless clusters do not assimilate: [lizd vartoctcovi] 'value letter', cf. [list-i] 'letter (nom. pl.)'. It is unknown whether this form is representative of a larger set of exceptions.
a. pajstfo 'state'
b. pajstf vrojix
'hostile nation'
c. zemst-a 'revenge'
d. $\quad$ zemst $\mathrm{v}^{\mathrm{j}}$ clcix
'great revenge (gen. pl.)'

The non-assimilation of voiceless clusters is shown with $/ \mathrm{zemst}^{\mathrm{j}} \mathrm{clcix} / \rightarrow$ [zemst v' $\mathrm{clcix}$ ' 'great revenge (gen. pl.)' (21d) in tableau (22). Despite violating AGREE(VOICE) and *[+VOICE], the fully faithful candidate (22a) is chosen as optimal. Fusing the voiceless [LAR] nodes (22b) does not improve on either markedness constraint, and superfluously violates UNIFORMITY(LAR). Likewise, fusing the second and third [LAR] nodes fatally violates UNIFORMITY(LAR) (22c) or IDENT(VOICE)-ONSET (22d). Deleting the middle [LAR] node (22e) improves on AGREE(VOICE), but fatally violates HAVELAR. Thus, unlike with voiced clusters, there is not a harmonically improving path to assimilate an underlyingly voiceless cluster. This falls out naturally from a serial derivation, and is advantageous over an analysis in parallel OT, which would require additional mechanisms to account for the difference between voiced and voiceless clusters. The word list noted above is problematic for this approach, but can for the time being be dismissed as exceptional.

\begin{tabular}{|c|c|c|c|c|c|}
\hline 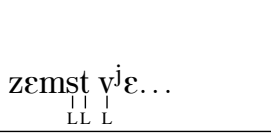 & 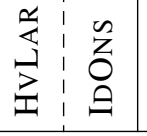 & \begin{tabular}{l}
$\sqrt[1]{11}$ \\
$\frac{1}{0}$ \\
\multirow{4}{4}{}
\end{tabular} & $\underset{\Sigma}{\stackrel{x}{z}}$ & $\begin{array}{l}0 \\
⿱ \\
+ \\
*\end{array}$ & 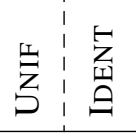 \\
\hline 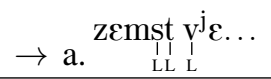 & $\begin{array}{l}1 \\
1 \\
1\end{array}$ & 1 & & 1 & $\begin{array}{l}1 \\
1 \\
1\end{array}$ \\
\hline 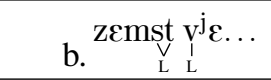 & 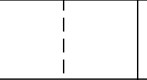 & 1 & & 1 & $\mathrm{~W} 1_{1}^{1}$ \\
\hline 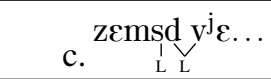 & 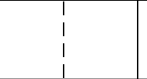 & 1 & & 1 & $\mathrm{~W} 1 \mathrm{~W} 1$ \\
\hline 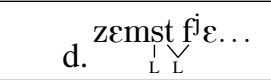 & W1 & $\mathrm{L}$ & & $\mathrm{L}$ & $\begin{array}{lll} & \\
\mathrm{W} 1 & \mathrm{~W} 1 \\
\end{array}$ \\
\hline e. e.mst $_{\substack{1 \\
\mathrm{~L}}}^{\mathrm{ze} \varepsilon \ldots}$ & $\mathrm{W} 1$ & $\mathrm{~L}$ & W1 & 1 & $\begin{array}{l}1 \\
1 \\
1\end{array}$ \\
\hline
\end{tabular}

Across syllable boundaries, codas assimilate to both [+voice] and [-voice] targets because IDENT(VOICE) does not distinguish between the operations that derive them. Within the onset, however, the relative ranking of IDENT(VOICE)-ONSET and MAX(LAR) only allows onset devoicing. This is apparent in the small set of words in (23), ${ }^{6}$ where vowel loss triggers devoicing. When the coda is underlyingly voiced, devoicing does not occur, e.g. [bes] 'lilac', [bz-i] 'lilac (nom. pl.)'. This indicates that agreement is more likely than a process that devoices onset clusters.
a. dex 'breath'
c. vef 'louse'
b. tx-u 'breath (gen. sg.)'
e. $\mathrm{v}^{\mathrm{j}} \varepsilon 6$ 'village'
d. $f \int-i$
'louse (nom. pl.)'
f. f6-i 'village (gen. sg.)'

Tableau (24) gives the derivation for $/ \mathrm{dxu} / \rightarrow$ [txu] 'breath (gen. sg.)' (23b). The fully faithful candidate [dxu] (24a) fatally violates AGREE(VOICE). Assimilating either onset obstruent (24b,c) fatally violates IDENT(VOICE)-ONSET. Though not shown, this constraint also rules out candidates in which the [LAR] nodes have fused. This leaves candidate $(24 \mathrm{~d})$, where the [+voice] [LAR] node is deleted. Deleting the second [LAR] node would fatally violate HAVELAR. The constraint ranking thus only permits onsets to devoice to

\footnotetext{
6 Cyran (2014) notes these forms show up in every analysis on the subject.
} 
satisfy AGREE(VOICE). Because [LAR] node deletion is only optimal in onset clusters, MAX(LAR)-ONSET is ranked exactly where MAX(LAR) is: below AGREE(VOICE) and above * [+VOICE]. However, this constraint does not contribute anything to the analysis and is excluded from discussion.

(24) $/ \mathrm{dxu} / \rightarrow[\mathrm{txu}]:$ Step 1

\begin{tabular}{|c|c|c|c|c|c|}
\hline $\begin{array}{l}\text { dxu } \\
11 \\
\mathrm{LL} \\
\end{array}$ & 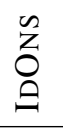 & 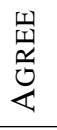 & $\underset{\Sigma}{\sum}$ & $\begin{array}{l}\vec{U} \\
> \\
\pm \\
*\end{array}$ & 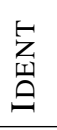 \\
\hline $\begin{array}{l}\operatorname{dxu} \\
11 \\
\text { a. } 11 \\
\mathrm{LL}\end{array}$ & & W1 & L & W1 & \\
\hline $\begin{array}{l}\text { txu } \\
\text { b. } 11 \\
\text { LL }\end{array}$ & W1 & & $\mathrm{L}$ & & W1 \\
\hline $\begin{array}{ll} & d y u \\
c . & 11 \\
\text { c } & \\
\end{array}$ & W1 & & L & W2 & W1 \\
\hline$\rightarrow$ d. ${ }_{\mathrm{L}}^{\mathrm{t} \times u}$ & & & 1 & & \\
\hline
\end{tabular}

With final OS clusters, the derivation for assimilation is similar to that for final devoicing. HAVELAR compels the [LAR] node to spread onto the word-final sonorant. This creates an adjacency between the [LAR] node and the left edge of the following word, which may incur a violation of AGREE(VOICE). Any such violations are resolved in the next step with regressive assimilation or node fusion.

The derivation of $/ \mathrm{v}^{\mathrm{j}}$ atr zaxodni/ $\rightarrow$ [ $\mathrm{v}^{\mathrm{j}}$ adr zaxodni] 'westerly wind' (4f) is given in tableaux (25-26). The first step is nearly identical to tableau (13): HAVELAR compels the final sonorant to acquire a [LAR] node. The relative ranking of DEP(LAR) and NOLINK(LAR) favors spreading the existing [LAR] node from the obstruent (25c) over inserting a new node (25b). Because the [LAR] node is voiceless, spreading it rightwards incurs a violation of AGREE(VOICE) with the following voiced obstruent. In the next step (26), this violation of AGREE(VOICE) is resolved by fusing the [LAR] nodes, keeping the [+voice] feature of the following onset (26b). Fusion is preferred over assimilation by *[+VOICE]; for space, the assimilation candidates are not shown. This approach does not require positing covert adjacency between the obstruents. Spreading the [LAR] node creates the local context for assimilation, obviating the need for a laryngeal tier. Reference to a tier is only necessary when AGREE(VOICE) is defined over obstruents.

\begin{tabular}{|c|c|c|c|c|}
\hline $\begin{array}{c}\mathrm{v}^{\mathrm{j}} \mathrm{atr} \\
\mathrm{L} \\
\mathrm{L} \\
\mathrm{L} \\
\end{array}$ & 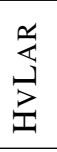 & 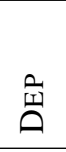 & 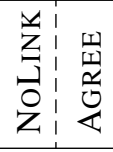 & 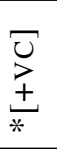 \\
\hline 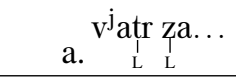 & W1 & & $\begin{array}{l:l} & \\
\mathrm{L} & \mathrm{L} \\
\end{array}$ & 1 \\
\hline 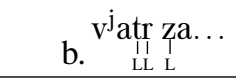 & & W1 & $\begin{array}{l:l} & \\
& \\
\mathrm{L} & 1 \\
\end{array}$ & W2 \\
\hline$\rightarrow$ c. $\mathrm{v}^{\mathrm{v}^{\mathrm{j}}} \underset{\mathrm{L}_{\mathrm{L}}}{\mathrm{V}} \mathrm{L}_{\mathrm{L}}^{\mathrm{za} . . .}$ & & & $\begin{array}{l:l} & \\
1 & 1 \\
\end{array}$ & 1 \\
\hline
\end{tabular}

(26)

\begin{tabular}{|c|c|c|c|c|c|}
\hline 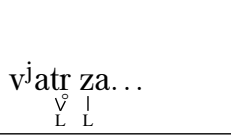 & 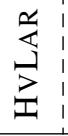 & $\begin{array}{l}n \\
\vdots \\
\vdots \\
1 \\
\vdots \\
1\end{array}$ & 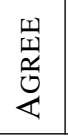 & $\begin{array}{l}\circlearrowright \\
> \\
+ \\
*\end{array}$ & 岂 \\
\hline 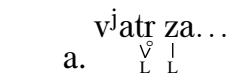 & & & W1 & 1 & $\mathrm{~L}$ \\
\hline$\rightarrow$ b. $\underbrace{\mathrm{v}^{\mathrm{j}} \mathrm{adr} z a . .}_{\mathrm{L}}$ & & & & 1 & 1 \\
\hline c. $\mathrm{v}_{\mathrm{L}}^{\mathrm{j}} \mathrm{s}_{\mathrm{L}}^{\mathrm{s}} \mathrm{sa} .$. & & W1 & & $\mathrm{L}$ & 1 \\
\hline d. ${ }^{v^{\mathrm{j}}}$ atr $\underset{\mathrm{L}}{\mathrm{z} a . . .}$ & W1 & & & 1 & $\mathrm{~L}$ \\
\hline
\end{tabular}

Tableaux (25-26) demonstrate agreement in OS\#O clusters. Non-agreement in O\#SO clusters follows straightforwardly from positional faithfulness constraints. HAVELAR dominates NOLINK(LAR), compelling [LAR] node spreading in the general case. However, HAVELAR is dominated by NOLINK(LAR)-INITIAL and DEP(LAR)-INITIAL, which ban spreading or inserting [LAR] nodes onto word-initial consonants. Wordinitial sonorants therefore do not acquire [LAR] nodes, bleeding the environment for assimilation. Preceding obstruents are therefore not shielded from final devoicing by AGREE(VOICE), and surface voiceless.

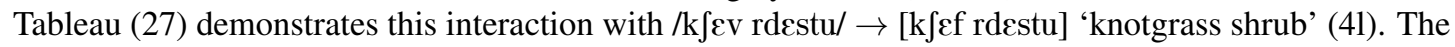
fully faithful candidate (27a) violates HAVELAR and * [+VOICE]. Satisfying HAVELAR by spreading (27b) or inserting a [LAR] node onto the initial sonorant (27c) fatally violates the positional faithfulness constraints. The optimal candidate $(27 \mathrm{~d})$, still violates HAVELAR, but improves on $*[+\mathrm{VOICE}]$ by devoicing the final 
obstruent. The asymmetry between OS\#O and O\#SO clusters thus follows from positional faithfulness constraints, which are independently motivated (Casali, 1997). By connecting the participation of sonorants to an unfaithful operation, the asymmetry falls out naturally.

(27) $/ \mathrm{k} \int \varepsilon v \mathrm{rd} \varepsilon \mathrm{stu} / \rightarrow\left[\mathrm{k} \int \varepsilon f\right.$ rdestu]: Step 1

\begin{tabular}{|c|c|c|c|c|c|c|c|}
\hline$\left.\left\langle\mathrm{k} \int \underset{\mathrm{L}}{\mathrm{L}} \underset{\mathrm{L}}{\mathrm{e}}\right\rangle\langle\underset{\mathrm{L}}{\mathrm{L}}\rangle\langle\rangle\right\rangle$ & $\begin{array}{l}\underline{\underline{Z}} \\
\text { 三 }\end{array}$ & $\frac{\underline{G}}{\underset{2}{2}}$ & 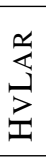 & $\stackrel{\stackrel{0}{\mid T}}{0}$ & 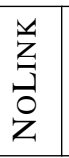 & $\begin{array}{l}\underset{\nu}{>} \\
+ \\
*\end{array}$ & 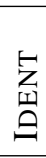 \\
\hline a. $\left.\underset{\mathrm{L}}{\left\langle\mathrm{k} \int \mathrm{ev}\right.}\right\rangle \underset{\mathrm{L}}{\mathrm{L}}\langle\underset{\mathrm{L}}{\mathrm{rdz} . . .\rangle}$ & & & 1 & & & W2 & $\mathrm{L}$ \\
\hline b. $\langle\underbrace{}_{\mathrm{L}}\left\langle\mathrm{k} \int \mathrm{ev}\right\rangle\left\langle\mathrm{L}_{\mathrm{L}}\langle\mathrm{rdz} .\rangle\right.$. & W1 & & $\mathrm{L}$ & & W1 & W2 & $\mathrm{L}$ \\
\hline c. $\left.\left.\left.\underset{\substack{1 \\
\mathrm{~L}}}{\left\langle\mathrm{k} \int \mathrm{ev}\right.}\right\rangle \underset{\substack{1 \\
\mathrm{~L}}}{\langle\mathrm{rdz}} \ldots\right\rangle\right\rangle$ & & W1 & $\mathrm{L}$ & W1 & & W3 & $\mathrm{L}$ \\
\hline$\rightarrow$ d. $\underset{\substack{L \\
L}}{\left\langle\mathrm{k} \int \mathrm{ef}\right\rangle} \underset{\mathrm{L}}{\mathrm{rdz} \ldots\rangle}$ & & & 1 & & & 1 & 1 \\
\hline
\end{tabular}

The constraint ranking is represented in the Hasse diagram in (28). The relations between sonorants acquiring laryngeal nodes, voice agreement, and final devoicing derive from the dominance relations between the three markedness constraints: HAVELAR $\gg$ AGREE(VOICE) $\gg *[+$ VOICE].

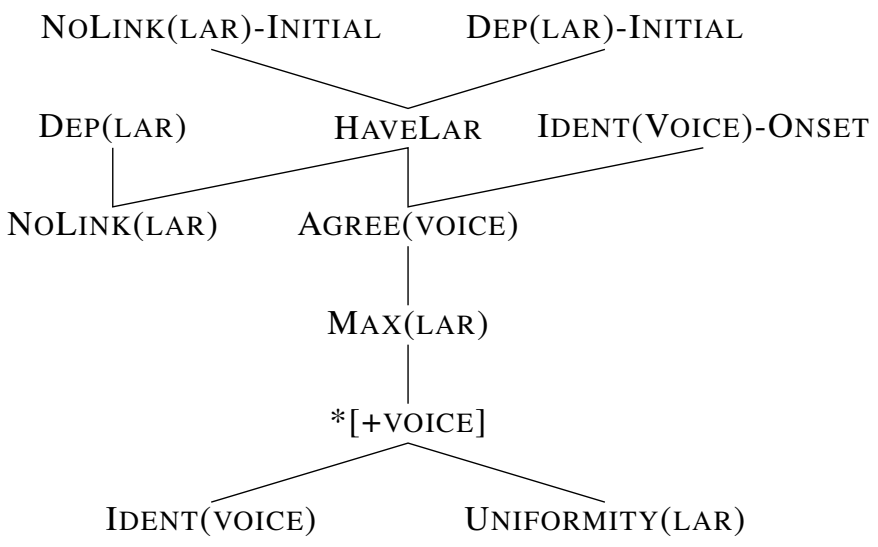

\section{Presonorant voicing}

Section 2 demonstrated the analysis of final devoicing and voice assimilation. Sonorants in OS clusters are coerced into participating in these processes by HAVELAR, which compels them to bear laryngeal nodes. The data in Section 2 concern sonorants as targets of these processes. This section demonstrates two environments where they behave as triggers of voice assimilation. Section 3.1 demonstrates how the analysis captures initial sonorants blocking final devoicing of preposition-final obstruents, and section 3.2 accounts for presonorant voicing in the dialect spoken in Cracow.

3.1 Prepositions Prepositions that end with obstruents are subject to final devoicing in isolation, e.g. [pot] 'under'. Before words beginning with obstruents, the preposition-final obstruents agree in voice (29ab). ${ }^{7}$ Remarkably, before sonorant- and vowel-initial words, these obstruents do not devoice (29c-f). This is unexpected because, even before vowel-initial words, these obstruents are not resyllabified as onsets; they are in coda position (Rubach \& Booij, 1990b; Rubach, 1996). In the Warsaw dialect, this leads to minimal pairs like [bes radoctci] 'lilac of joy' and [bez radoctci] 'without joy'. In the same segmental environment, final devoicing targets the noun bez 'lilac', but not the preposition bez 'without'.

\footnotetext{
7 This has been reported for the set of prepositions that end with underlyingly voiced obstruents. It is not clear whether the same is true of prepositions with final voiceless obstruents, e.g. [obok] 'beside'. If this set does not assimilate to voiced obstruents, then they behave like onsets, motivating an IDENT constraint indexed to prepositions (Smith, 2011).
} 

a. pot pwotem
'by the fence'
b. pod bramow
'by the gate'
c. pod mostem
'under the bridge'
d. pod əcem
'under the eye'
e. pod rtentc ${ }^{\mathrm{j}} \partial \tilde{\mathrm{w}}$
'under the mercury'
f. nad mxem
'over the moss'

Prepositions have been argued to form a single prosodic word with their arguments (Rubach, 1996; Gussmann, 2007). This means that the sonorants in (29c-f) are not in word-initial position, and therefore subvert the positional faithfulness constraints NOLINK(LAR)-INITIAL and DEP(LAR)-INITIAL, which are responsible for devoicing in O\#SO clusters (27). Tableaux (30-31) demonstrate why devoicing is blocked with /pod mostem/ $\rightarrow$ [pod mostem] 'under the bridge' (29c).

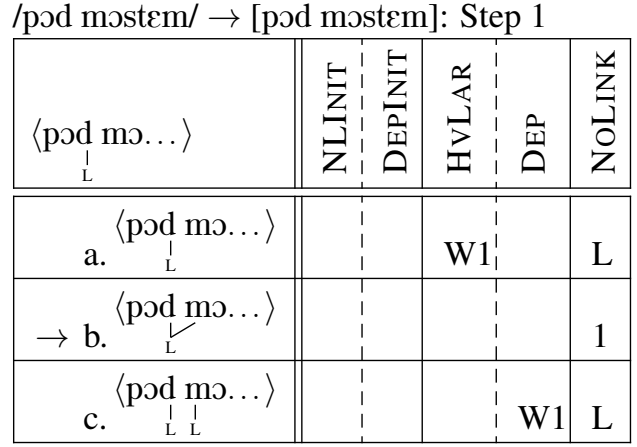

(31)

\begin{tabular}{|c|c|c|c|c|c|}
\hline$\langle\underset{\mathrm{L}}{\langle\operatorname{pod} \operatorname{mo} . .}\rangle$ & $\begin{array}{ll} \\
\mid\end{array}$ & $\overbrace{0}^{2}$ & $\stackrel{x}{\Sigma}$ & $\begin{array}{l}\bar{\tau} \\
⿱ 亠 \\
\pm \\
*\end{array}$ & 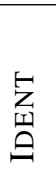 \\
\hline$\rightarrow$ a. ${ }_{\mathrm{L}}^{\langle\operatorname{pod} \operatorname{mo} . .\rangle}$ & & & & 1 & \\
\hline b. $\underbrace{}_{L}\left\langle\operatorname{pot} \cos ^{\prime} \ldots\right\rangle$ & & W1 & & $\mathrm{L}$ & W1 \\
\hline c. $\langle$ pot mo... $\rangle$ & $\mathrm{W} 1$ & & $\mathrm{~W}$ & $\mathrm{~L}$ & \\
\hline
\end{tabular}

In the first step (30), the [LAR] node associated with the final obstruent of the preposition links to the initial sonorant of the noun (30b). This does not violate NOLINK(LAR)-INITIAL, because the sonorant is not in word-initial position. Not linking the [LAR] node to the sonorant (30a) fatally violates HAVELAR, and inserting a new node (30c) violates DEP(LAR). In the next step (31), the fully faithful candidate (31a) violates * [+VOICE], but is chosen as optimal, and the derivation converges. Satisfying * [+VOICE] by devoicing (31b) is ruled out by IDENT(VOICE)-ONSET, because the [LAR] node is associated with the onset sonorant in mostem, and deleting the [LAR] node (31c) fatally violates HAVELAR.

Prepositions are thus able to subvert word-initial faithfulness by incorporating into the same prosodic words as their arguments. While HAVELAR compels the initial sonorants to bear [LAR] nodes, this does not compel voicing of the obstruents in SO-initial words (29e-f), e.g. [nad mxem] *[nad myem] 'over the moss' (29f). This follows from onsets only being able to devoice in this environment (24). Within the onset, the violation of AGREE(VOICE) triggers the deletion of the [LAR] node associated with the voiceless obstruent.

3.2 Cracow voicing Another context where sonorants are triggers of voice assimilation is found in the dialect spoken in Cracow. In Cracow Polish, obstruents are voiced word-finally before words beginning with sonorants; the facts are otherwise identical to Warsaw Polish (Rubach, 1996). This triggers voicing of underlyingly voiceless obstruents as in (32a-b), cf. [brat-a] 'brother (gen. sg.)', and blocks final devoicing of underlyingly voiced obstruents as in (32c-d), cf. [samoxod-u] 'car (gen. sg.)'. As with prepositions, resyllabification does not apply across word boundaries, and word-final consonants are parsed as codas even intervocalically, as in [brad jjtsa] 'father's brother' (32b) (Rubach \& Booij, 1990b; Rubach, 1996).
a. brad naf 'our brother'
'the car is shining'
b. brad ojtsa
'father's brother'
c. samoxud loj
d. samoxud ojtsa
'father's car'

In this analysis, the difference between Warsaw and Cracow Polish derives from the ranking between DeP(LAR)-INitial and HaveLAR. In Warsaw Polish, [LAR] node epenthesis is blocked at the left-edge of a word, and the asymmetry between OS\#O and O\#SO clusters emerges (27). In Cracow Polish, the ranking is reversed, and word-initial sonorants acquire [LAR] nodes, creating [LAR] node clusters. AGREE(VOICE) then triggers assimilation of preceding voiceless obstruents or blocks final devoicing. This derivation also requires HaVelar to dominate DeP(LAR) in Cracow Polish. Warsaw Polish may also have this ranking, but that cannot be established from the data. Capturing this difference between the dialects with a single constraint reranking is simpler than other approaches, such as analyzing Warsaw Polish as marking [+voice] and Cracow Polish as marking [-voice] (Cyran, 2014). As in (29e-f), inserted [LAR] nodes do not affect initial SO-clusters, as onsets only devoice to agree, e.g. [samoxud løni] *[samoxud lzni] 'the car is shining' (32c). 
Tableaux (33-34) give the derivation of /brat naf/ $\rightarrow$ [brad naf] 'our brother' (32a) in Cracow Polish. In the first step (33), HAVELAR is satisfied by inserting a [LAR] node onto the initial sonorant of nasz (33c). ${ }^{8}$ This context differentiates between inserting and linking [LAR] nodes. Linking the [LAR] node (33b) satisfies HAVELAR, but would ultimately produce a voiceless cluster: voicing the linked node at a later step would be blocked by *[+VOICE] and the IDENT constraints. There is no derivational path to voice the $/ t /$ that begins with linking it to the following sonorant. Inserting the [LAR] node creates a violation of AGREE(VOICE), which motivates regressive assimilation in the next step of the derivation (34). Because assimilation is to a voiced segment, fusion (34b) is preferred over assimilation (not shown).

\begin{tabular}{|c|c|c|c|c|c|}
\hline$\underset{\substack{L \\
L}}{\langle\text { brat }}\rangle\langle$ na $\rangle$ & $\begin{array}{l}\stackrel{\Xi}{\mathbf{z}} \\
\mathrm{Z}\end{array}$ & $\underset{3}{\stackrel{3}{3}}$ & 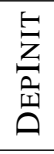 & 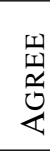 & $\begin{array}{l}\bar{U} \\
⿱ \\
+ \\
*\end{array}$ \\
\hline$\underset{\mathrm{L}}{\langle\text { brat }\rangle\langle\mathrm{na} J\rangle}$ & & W1 & $\mathrm{L}$ & $\mathrm{L}$ & $\mathrm{L}$ \\
\hline b. $\underbrace{\langle\text { brat }\langle\text { naf }\rangle}_{\mathrm{L}}$ & W1 & & $\mathrm{L}$ & $\mathrm{L}$ & $\mathrm{L}$ \\
\hline 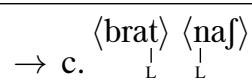 & & & 1 & 1 & 1 \\
\hline
\end{tabular}

(34)

\begin{tabular}{|c|c|c|c|c|c|}
\hline 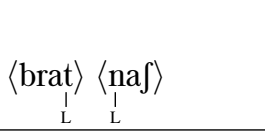 & $\begin{array}{l}n \\
z \\
O \\
\Leftrightarrow\end{array}$ & 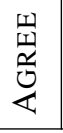 & $\sum^{x}$ & $\begin{array}{l}\bar{J} \\
\geq \\
\pm \\
*\end{array}$ & 崖 \\
\hline 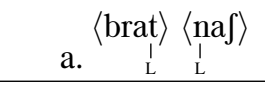 & & $\mathrm{W} 1$ & & 1 & $\mathrm{~L}$ \\
\hline$\rightarrow$ b. ${ }_{\mathrm{L}}^{\langle\mathrm{brad}\rangle}\langle\mathrm{na}\rangle$ & & & & 1 & 1 \\
\hline c. $\langle\underbrace{\langle\text { brat }\rangle}_{\mathrm{L}}\langle$ na $\rangle$ & W1 & & & $\mathrm{L}$ & 1 \\
\hline d. $\langle$ brat $\rangle \underset{\substack{\mathrm{L} \\
\mathrm{L}}}{\langle\mathrm{na}\rangle}\rangle$ & & & W1 & 1 & L \\
\hline
\end{tabular}

\section{Discussion}

The analysis presented in this paper accounts for the patterns in Polish by positing a novel markedness constraint, HAVELAR, that compels sonorants to bear laryngeal nodes in OS clusters. In concert with defining the familiar constraints * [+VOICE] and AGREE(VOICE) over laryngeal nodes rather than over a specified set of segments, this captures the reported data. Defining these markedness constraints in terms of laryngeal nodes is desirable because the set of obstruents is not necessarily exactly the set of segments targeted by final devoicing and voice assimilation (Hall, 2003). By referring to laryngeal nodes, the set of targets can be determined on a language-specific basis by determining the set of segments that possess [LAR] nodes.

HAVELAR allows sonorants to behave both as targets and triggers of these processes without positing a large number of constraints. It also avoids analyzing assimilation in OS\#O clusters as occurring at a distance. A long-distance approach naturally raises questions about OVO contexts, where obstruents are separated by a vowel. In Rubach's (1996) analysis, vowels behave like sonorants, acquiring laryngeal nodes after being syllabified, and intervening between obstruents on the laryngeal tier. That approach is problematic here, because the presence of a voiced [LAR] node would block final devoicing in OVO words through the action of AGREE(VOICE). However, denying vowels laryngeal nodes leaves an explanatory lacuna in the lack of final devoicing in prepositions, e.g. [pod ocem] 'under the eye' (29d), and voicing in Cracow Polish, e.g. [brad jitsa] 'father's brother' (32b). One possible approach is to exploit the fact that these are the only contexts in which VCV sequences are syllabified with codas, positing an interaction between positional faithfulness and a constraint against intervocalic voicelessness. This is one aspect of the analysis to be returned to in future work.

HAVELAR also raises a number of questions about its scope and nature, which motivate future typological and experimental work. It is unknown whether HAVELAR is specific to Polish or active in other languages or whether it belongs to a larger family of HAVEFEATURE constraints. Whether it is phonetically grounded is also an important question. This paper aimed to propose a formal explanatory mechanism of the data within the context of Harmonic Serialism and necessarily must leave these questions to future work.

Setting aside the sonorants, the behavior of obstruents is also theoretically interesting. Polish exhibits an asymmetry between codas and onsets, where the former assimilate to voiced and voiceless targets and the latter only assimilate to voiceless targets. In the context of this analysis, this motivates both MAX and IDENT constraints, softening the dichotomy between them (McCarthy, 2008). Because the set of words with onset

\footnotetext{
8 GEN is assumed to only insert voiced [LAR] nodes.
} 
devoicing is so limited, the behavior of prepositions with final voiceless obstruents needs to be examined further. Despite the complexity of the data commonly reported, there is still more to account for.

Finally, the behavior of final voiceless clusters in assimilation contexts demands further study, especially phonetically. This analysis demonstrated that HS predicts that they should remain voiceless in these contexts, while parallel OT does not. This is a testable difference between the theories that should prove interesting.

\section{Conclusion}

The processes of final devoicing and voice assimilation in Polish are remarkable for the way they are reported to interact with sonorants. Previous analyses have ascribed these interactions to the presence or absence of sonorants in the prosodic structure when the appropriate rules apply. This paper argued that the data can be modeled by analyzing sonorants as acquiring laryngeal nodes, making them susceptible to the same constraints targeting obstruents. It was shown that the analysis neatly extends to the presonorant voicing patterns found in prepositions and in the Cracow dialect.

\section{References}

Beckman, Jill (1998). Positional faithfulness. Ph.D. thesis, University of Massachusetts, Amherst.

Bethin, Christina (1992). Polish syllables: The role of prosody in phonology and morphology. Slavica Publishers, Inc., Columbus, $\mathrm{OH}$.

Bethin, Christina (2011). Polish syllable structure. van Oostendorp, Marc, Colin Ewen, Elizabeth Hume \& Keren Rice (eds.), The Blackwell Companion to Phonology, Wiley-Blackwell, Malden, MA, 2609-2630.

Casali, Roderic F. (1997). Vowel ellision in hiatus contexts: Which vowel goes? Language 73:3, 493-533.

Cyran, Eugeniusz (2014). Between phonology and phonetics: Polish voicing. Mouton de Gruyter, Berlin.

Elfner, Emily (2009). Syllabification and stress-epenthesis interactions in Harmonic Serialism. Unpublished manuscript. Gussmann, Edmund (2007). The phonology of Polish. Oxford University Press, Oxford.

Hall, Daniel Currie (2003). Laryngeal feature specifications in West Slavic languages. Toronto Working Papers in Linguistics 20, 93-114.

Inkelas, Sharon (1995). The consequences of optimization for underspecification. Beckman, Jill (ed.), Proceedings of NELS 25, GLSA Publications, Amherst, MA, 287-302.

Jesney, Karen (2011). Positional faithfulness, non-locality, and the Harmonic Serialism solution. Lima, Suzi, Kevin Mullin \& Brian Smith (eds.), Proceedings of NELS 39, GLSA, Amherst, MA, 403-416.

Lombardi, Linda (1991). Laryngeal features and laryngeal neutralization. Ph.D. thesis, University of Massachusetts, Amherst.

Lombardi, Linda (1995). Laryngeal neutralization and syllable wellformedness. Natural Language \& Linguistic Theory 13:1, 39-74.

Lombardi, Linda (1999). Positional faithfulness and voicing assimilation in Optimality Theory. Natural Language \& Linguistic Theory 17, 267-302.

McCarthy, John J. (2000). Harmonic serialism and parallelism. Hirotani, Masako, Andries Coetzee, Nancy Hall \& Ji-yung Kim (eds.), Proceedings of NELS 30, GLSA, Amherst, MA, 501-524.

McCarthy, John J. (2008). The gradual path to cluster simplification. Phonology 25:2, 271-319.

McCarthy, John J. (2016). The theory and practice of Harmonic Serialism. McCarthy, John J. \& Joe Pater (eds.), Harmonic Grammar and Harmonic Serialism, Equinox Publishing, London, 47-87.

Prince, Alan \& Paul Smolensky (1993/2004). Optimality Theory: Constraint Interaction in Generative Grammar. Blackwell Publishing, Malden, MA.

Rubach, Jerzy (1996). Nonsyllabic analysis of voice assimilation in Polish. Linguistic Inquiry 27:1, 69-110.

Rubach, Jerzy (1997). Extrasyllabic consonants in Polish: Derivational Optimality Theory. Roca, Iggy (ed.), Derivations and constraints in phonology, Clarendon Press, Oxford, 551-581.

Rubach, Jerzy (2008). Prevocalic faithfulness. Phonology 25:3, 433-468.

Rubach, Jerzy \& Geert E. Booij (1990a). Edge of constituent effects in Polish. Natural Language \& Linguistic Theory $8: 3,427-463$.

Rubach, Jerzy \& Geert E. Booij (1990b). Syllable structure assignment in Polish. Phonology 7:1, 121-158.

Smith, Jennifer L. (2011). Category-specific effects. van Oostendorp, Marc, Colin Ewen, Elizabeth Hume \& Keren Rice (eds.), The Blackwell Companion to Phonology, Wiley-Blackwell, Malden, MA, 2439-2463.

Strycharczuk, Patrycja (2012). Sonorant transparency and the complexity of voicing in Polish. Journal of Phonetics 40, 655-671.

Torres-Tamarit, Francesc (2012). Syllabification and opacity in Harmonic Serialism. Ph.D. thesis, Centre de Lingüística Teòrica.

Wetzels, Leo \& Joan Mascaró (2001). The typology of voicing and devoicing. Language 77:2, 207-244.

Wheeler, Max W. (2005a). The Phonology of Catalan. Oxford University Press, Oxford.

Wheeler, Max W. (2005b). Voicing contrast: licensed by prosody or licensed by cue? Paper presented at mfm 13. 